\title{
Solar reflectance of ETICS finishing coatings - a comparison of experimental techniques
}

\author{
Nuno M. M. Ramos ${ }^{1, *}$, Andrea R. Souza ${ }^{1}$, Joana Maia ${ }^{1}$, and Ricardo M. S. F. Almeida ${ }^{1,2}$ \\ ${ }^{1}$ CONSTRUCT (LFC), Faculty of Engineering (FEUP), University of Porto, Portugal \\ ${ }^{2}$ Department of Civil Engineering, Polytechnic Institute of Viseu, Portugal
}

\begin{abstract}
The solar reflectance has a significant role in the thermal behaviour and surface temperature of ETICS finishing coats. Incomplete information of solar reflectance of ETICS with nanopigments can sometimes difficult their adequate selection. In this work, the solar reflectance of different ETICS finishing coats was measured using two distinct methodologies, and the importance of the adopted procedure was discussed. The experimental methodologies used were: i) the adapted conventional pyranometer technique (non-ASTM E1918A), which measures the global solar reflectance; and ii) the use of the spectrophotometry, to measure the spectral reflectance. It was verified that the E1918A methodology is more sensitive to environmental conditions than the spectrophotometry procedure. Also, the calculation of solar reflectance with spectrophotometer can be carried out by the 50 or 100 ordinates. However, the surface characteristics, as the concentration of pigments and roughness, affect more the solar reflectance measured with the spectrophotometer than with the pyranometer. It was verified that the nanopigments could improve solar reflectance and change the spectral reflectance. The results showed that, if the procedure is well applied, both methodologies could be used to evaluate the advantages of incorporating nanopigments in façade finishing coatings and also to assess the durability of these materials.
\end{abstract}

\section{Introduction}

The improvement of the thermal performance of building envelopes is often necessary to meet the requirements of energy efficiency in buildings both new and refurbished. The External Thermal Insulation Composite Systems with rendering (ETICS) is widely used in North America and Europe as a façade thermal barrier. However, this kind of building thermal envelope is very sensitive to thermal stresses [1].

Surfaces with low solar reflectance absorb a high fraction of energy into the façade leading to higher surface temperature [2]. The solar reflectance of the ETICS can be controlled using lighter colours, however, in recent years, there has been an architectural aesthetic demand for dark colours, leading to a higher temperature of the ETICS surface. The application of nanomaterials is one way of increasing the reflectance the surface finishing [1].

The European Guideline for Application of ETICS (EAE) [3] recommends that to avoid the thermal stress the finish coatings should have a solar reflectance higher than 0.7 , and the thickness between 2 and $7 \mathrm{~mm}$. In this way, the determination of solar reflectance can help designers and consumers to choose the proper colours to make the buildings and communities energy efficient [2].

Measuring the solar reflectance of an ETICS façade is essential to estimate the solar absorption and the thermal stress of the surface. Studies done by Akbari, Levinson and Berdahl [4], Akbari et al. [5], Fernández-García et al. [6] and Chen et al. [7] show that the solar reflection values are influenced by the measurement procedure, environmental conditions, and the properties of the material of the surface.

Different measurement methods for obtaining surface solar reflectance can be found in international standards of the American Society for Testing and Materials (ASTM). Such methods use different measuring equipment and are suitable for the evaluation of surfaces with different characteristics. The literature review showed that the measurement of solar reflectance depends on the field and environmental conditions, and the properties of the materials (rough or bright). Although, have many studies about the coating materials, the measurements of the albedo have mainly focus on pavement and roof coatings [7].

This article explores the different techniques for measuring solar reflectance for the ETICS finish layer. Evaluating different properties of surfaces, such as colour and incorporation of nanopigments.

\section{Solar radiation}

Solar radiation reaches the surface of the earth as electromagnetic radiation in the wavelength range from 280 to $2500 \mathrm{~nm}$. Fig. 1 presents the solar distribution according to ASTM G173 [8].

The ultraviolet (UV) region corresponds to about 5\% of the sunlight energy; this radiation increases the photodegradation of organic coatings. The visible region (VIS) corresponds to the colours aspect and is responsible for about $42 \%$ of the solar energy. The other $53 \%$ of the energy is produced in the infrared region (IR) [9].

\footnotetext{
${ }^{*}$ Corresponding author: nmmr@fe.up.pt
} 


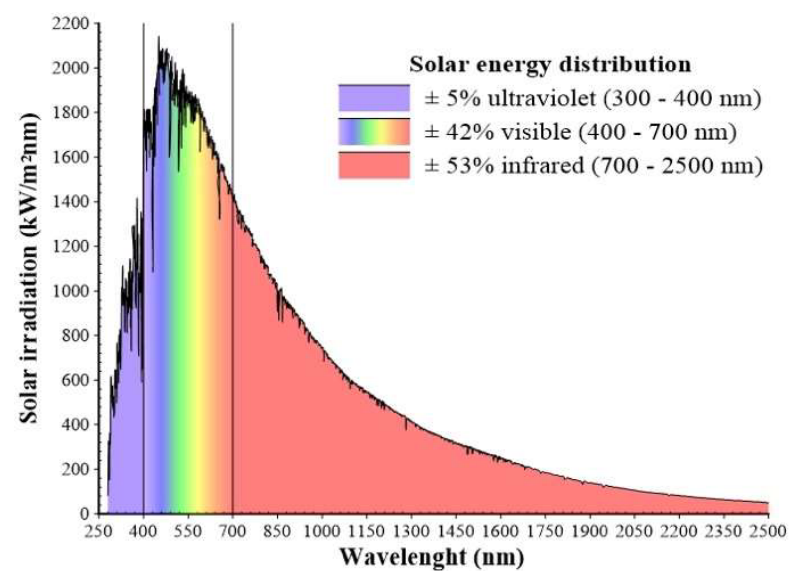

Fig. 1. Total solar irradiance.

The capacity of construction materials to reflect solar radiation is defined as the ratio of the global solar radiation reflected by a surface to the global solar radiation incident on it. It is independent of the incidence angle for diffuse reflectors, while for mirror-like materials, it increases with the angle of incidence, according to Fresnel equation [10,11].

The solar reflectance, or albedo, is a dimensionless fraction and is measured on a scale from 0 to 1 . An albedo of 0 means no reflecting power of a perfectly black surface (none reflected, all absorbed), an albedo of 1 means perfect reflection of a perfectly white surface (100\% reflected) [12].

The solar reflectivity of a surface depends upon material properties such as colour, surface roughness, and the presence of impurities. Measuring the solar-weighted solar reflectance of opaque surfaces requires instruments capable of measuring cumulative spectral reflectance values over the whole solar spectrum. Over the years, models have been proposed to approach the solarweighted spectral reflectance by a combination of measurements with portable and laboratory devices $[6,11]$.

For very smooth and highly polished surfaces the specular reflector it is more significant than the diffuse component. While for rough surfaces, will be the opposite, the most significant contribution to the solar reflectance is the diffuse component [13].

The commercial instruments available to measure reflectance are the spectrophotometers, the reflectometers, and the pyranometers [14]:

- The spectrophotometer is a photometer that can measure intensity as a function of the light source wavelength. It is commonly used to measure transmittance, absorptance and reflectance of opaque materials. This equipment can measure reflectance for the whole solar spectrum [6];

- The reflectometers are devices that measure the intensity of the light source after reflection on a specimen without wide spectral information, that is, they are equipped with light sources that radiate only one or a few narrow wavelength lines or bands. The reflectometers are standard calibrated to measure the specular reflectance for the wavelength that is near the solar energy peak between wavelength $500 \mathrm{~nm}$ and $660 \mathrm{~nm}[6]$;

- The pyranometer is an actinometer used for measuring the solar irradiance on a flat receiver surface which results from the radiant fluxes incident from the hemisphere above within the wavelength range from approximately $300 \mathrm{~nm}$ to about $3000 \mathrm{~nm}$ [15].

According to the instrument, different standards and procedures were developed by ASTM. Levinson, Akbari and Berdahl $[4,14,16]$ in their studies evaluate the accuracy and errors of the procedures and the influence of the environment.

The measurement of the solar reflectance using specific equipment is currently described by the ASTM standards: C1549 (reflectometer), E903 (spectrophotometer) and E1918 (pyranometer).

The ASTM C1549 presents the determination of solar reflectance by reflectometer: Standard test method for determination of solar reflectance near ambient temperature using a portable solar reflectometer. The standard recommends that the measurement area should be approximately $5 \mathrm{~cm}^{2}$, and the procedure is best applicable to flat and homogenous surfaces [5].

The ASTM E903 defines the utilisation of the spectrophotometer: Standard test method for solar absorptance, reflectance, and transmittance of materials using integrating spheres. For this procedure, it is recommended that the measurement area should be approximately $0.1 \mathrm{~cm}^{2}$ and is best applicable to flat and homogenous surfaces [5].

The spectrophotometer can measure the reflectance of the whole solar spectrum with a recommended wavelength interval of $5 \mathrm{~nm}$. According to the equipment specifications, the measurement can take several minutes, the beam typically illuminates approximately $100 \mathrm{~mm}^{2}$, is recommended for homogeneous specimens and a series of measurements at a single point should be taken. This procedure can be applied in both horizontal and vertical surfaces, adjusting the reflection angle [16]. The spectrophotometer, as the reflectometer, can be used in field measurements, although more accurate results will be achieved in a laboratory with controlled environmental conditions.

Method E903 specifies that the solar reflectance of a terrestrial surface should be calculated by a weighted average with a standard of selected solar spectral irradiance as the weighting function by either the directed calculation of suitable convolution integrals or the weighted or selected ordinate method [17].

The ASTM E1918 describes the pyranometer use: Standard test for measuring solar reflectance of horizontal and low-sloped surfaces in the field. This methodology is recommended for large (10 $\mathrm{m}^{2}$ of an area) rough or nonuniform surfaces. The non-ASTM E1918A procedure can be used on smaller surfaces, but not smaller than $1 \mathrm{~m}^{2}$ [4].

The ASTM E1918 or non-ASTM E1918A is applied for flat or near-flat surfaces, with a slope smaller than $9.5^{\circ}$. The measurements should be taken under a clear sky, without clouds or haze, and during the period that the sun has a normal angle with the surface smaller than $45^{\circ}$. This angle limits the test between the 9 a.m. and 3 p.m. period, depending on the latitude location of the test [18]. 
The non-ASTM E1918A was developed by Akbari, Levinson and Stern [5] for measuring the solar reflectance of small specimens with diffusely reflective surface. It is widely used to measure the solar reflectance of rough coatings, mainly on roofs and pavements.

\section{Materials and Methods}

\subsection{Materials}

The proposed methodology was applied to a set of specimens constituted by three distinct layers, Fig. 2a. The finishing coating (1) consists of a thin layer of mortar of approximately $2 \mathrm{~mm}$. The base coat (2) is applied in two layers of $1.5 \mathrm{~mm}$ each with a glass fibre mesh between them. The insulation slab (3) has a thickness of 4 $\mathrm{cm}$, constitute either of expanded polystyrene (EPS) or thermal render (TR).

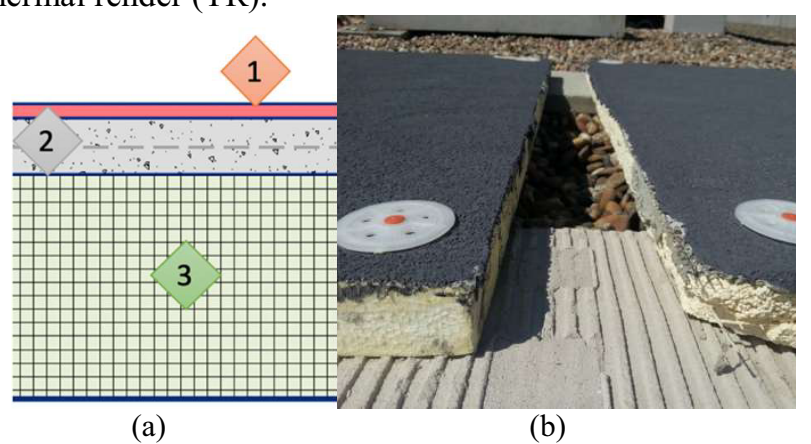

Fig. 2. Specimens layers. (a) Generic layout. (b) Real specimen.

The finishing coating is an organic plaster coating composed by mineral fillers, resins in aqueous dispersion, pigments and specific additives (antifungal and others). The base coat mortar is a mixture of cement, resins, mineral fillers, synthetic fibbers and specials additives. The insulation slab of EPS has a density of $20 \mathrm{~kg} / \mathrm{m}^{3}$, and the TR is a projected mortar, containing lime, mineral fillers, EPS granules and special additives. The constitution of the specimens can be seen in Fig. $2 b$.

Nanopigments were added to some of the finishing coatings to modify the reflective property of the layer. The used nanopigment is a commercial NIR black PBr29.

The Id. of the specimens and their constitution are given in Table 1.

Table 1. Constitution of specimens

\begin{tabular}{|c|c|l|}
\hline Id. & Substrate & \multicolumn{1}{c|}{ Finishing coating } \\
\hline TB0 & TR & Black colour without nanopigment \\
\hline TB1 & TR & Black colour with nanopigment \\
\hline EB0 & EPS & Black colour without nanopigment \\
\hline EB1 & EPS & Black colour with nanopigment \\
\hline ER0 & EPS & Red colour without nanopigment \\
\hline ER1 & EPS & Red colour with nanopigment \\
\hline EY0 & EPS & Yellow colour without nanopigment \\
\hline EG0 & EPS & Green colour without nanopigment \\
\hline EBL0 & EPS & Blue colour without nanopigment \\
\hline EO0 & EPS & Orange colour without nanopigment \\
\hline ELB0 & EPS & Light brown without nanopigment \\
\hline EDB0 & EPS & Dark brown without nanopigment \\
\hline
\end{tabular}

\subsection{Solar reflectance measurements}

The evaluation of solar absorptance carried out by the non-ASTM E1918A procedure was proposed by Akbari and Levinson [4] and consisted of an adaptation of the ASTM E1918 [18]. This procedure uses a pyranometer to measure the incident and reflected radiant solar energy in a $1 \mathrm{~m}^{2}$ surface.

In this research, an SR05 Hukseflux Thermal Sensors pyranometer was used, which presents an estimated precision of $4.4 \%$.

The measurement procedure described in E1918A consists of:

i. Place the pyranometer in the middle of the specimen, avoiding shadowing the measurement area;

ii. Set the pyranometer upward to read incoming solar radiation $\left(\mathrm{I}_{\mathrm{H}}\right)$;

iii. Turn the pyranometer downward to read reflected solar radiation by the white mask $\left(\mathrm{I}_{1}\right)$ followed by the reading of the black mask $\left(\mathrm{I}_{2}\right)$ and at last by the specimen $\left(\mathrm{I}_{3}\right)$;

iv. Spin the pyranometer upward to read the incoming solar radiation ( $\mathrm{I}_{\mathrm{H}}$ ) again.

The following conditions must be taken into account:

- If the difference, in modulus, between I' ${ }_{\mathrm{H}}$ and $\mathrm{I}_{\mathrm{H}}$ is higher than $20 \mathrm{~W} / \mathrm{m}^{2}$, steps two and three need to be remade;

- All the five readings should be taken under ten minutes, and after each spin of the pyranometer, one must wait thirty seconds to the read to be stabilised.

After the readings, the solar reflectance can be calculated by Eq. (1).

$$
R_{t}=R_{b}+\frac{I_{3}-I_{2}}{I_{1}-I_{2}}\left(R_{w}-R_{b}\right)
$$

Where:

$\mathrm{R}_{\mathrm{t}}$ : reflectance;

$\mathrm{R}_{\mathrm{b}}$ : reflectance of black mask;

$\mathrm{R}_{\mathrm{w}}$ : reflectance of white mask;

$\mathrm{I}_{1}$ : reflected solar radiation of white mask $\left[\mathrm{W} / \mathrm{m}^{2}\right]$;

$\mathrm{I}_{2}$ : reflected solar radiation of black mask $\left[\mathrm{W} / \mathrm{m}^{2}\right]$;

$\mathrm{I}_{3}$ : reflected solar radiation of specimen $\left[\mathrm{W} / \mathrm{m}^{2}\right]$.

It is necessary to take three readings of reflectance according to described steps. The reflectance of the specimen will be the average between three measurements. Conditioned that the amplitude of the three calculated reflectance should be lower than 0.02 .

All the process is schematically represented in Fig. 3.

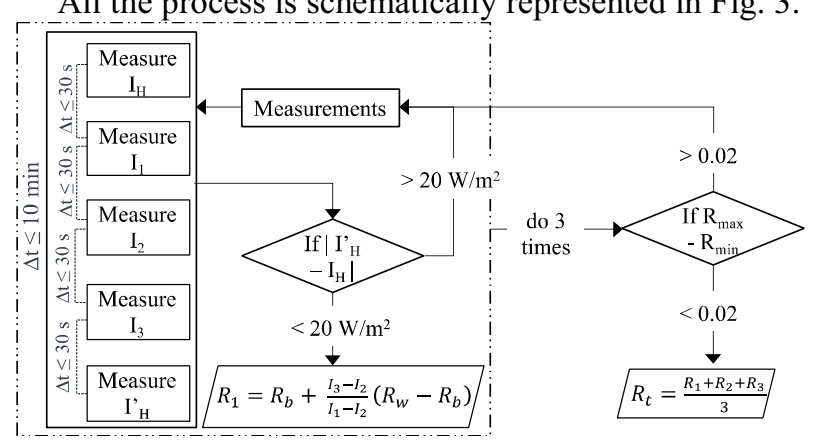

Fig. 3. Flowchart of the non-ASTM E1918A methodology. 
According to Levinson, Akbari and Berdahl [16] in the case of a rough surface, it is recommended to made measurements in different points of the specimens. Beside this, the roughness surface do not present a significant specular component [10].

Complementary the measurement of solar reflectance with pyranometer, a spectrophotometer was used to evaluate the influence of the roughness, the nanopigment and the spectral reflectance of the specimens.

In this research, the diffuse solar reflectance were measured using a modular spectrophotometer (FLAME-T and FLAME-NIR Ocean Optics). This modular spectrophotometer combines light from halogen and deuterium filaments delivered to a $4.5 \mathrm{~mm}$ fibber diameter port. The optical fibber emitted these beam in the specimen, and the reflected light beam is read. The output of the test is the diffuse reflectance spectrum, measured at $10 \mathrm{~nm}$ wavelength intervals ranging from 190 to $1650 \mathrm{~nm}$.

To calculate the solar reflectance, the ordinates method of the ASTM E903 was chosen. In this method, the solar irradiance distribution is divided into $n$ wavelength intervals, each containing $1 / n$ of the total irradiance [17].

The measurement procedures are:

i. The light source has to be warming for 30 minutes before the test, once the light beam has to stabilize;

ii. The software has to be calibrated with the information of scans to average and boxcar width to reduce the noisy of the chart;

iii. After the software is ready, it is necessary to do the spectrophotometer calibration. First, it is necessary to the reflectance of the standard specimen with the black and white background;

iv. Following the measurement of the reflectance of the specimen can be carried out;

v. Given the reflectance spectrum of the specimen, a data table of ordinates needs to be export.

The solar reflectance is then calculated by Eq. (2) [17].

$$
\rho_{s}=\frac{1}{n} \sum_{i=1}^{n} \rho\left(\lambda_{i}\right)
$$

Where:

$\rho_{\mathrm{s}}$ : reflectance of the specimen; or 100 ;

$\mathrm{n}$ : number of ordinate in the integrating sphere, 50

$\rho \lambda_{\mathrm{i}}$ : reflectance of wavelength on ordinates derived from Tables G173 in Appendix X2 ASTM E903 [17].

In this research, the solar reflectance calculation was made using both 50 and 100 selected ordinates.

\section{Results and discussion}

Fig. 4 presents the values of solar reflectance for the 12 specimens, according to the pyranometer measurements proceedings (non-ASTM E1918A).

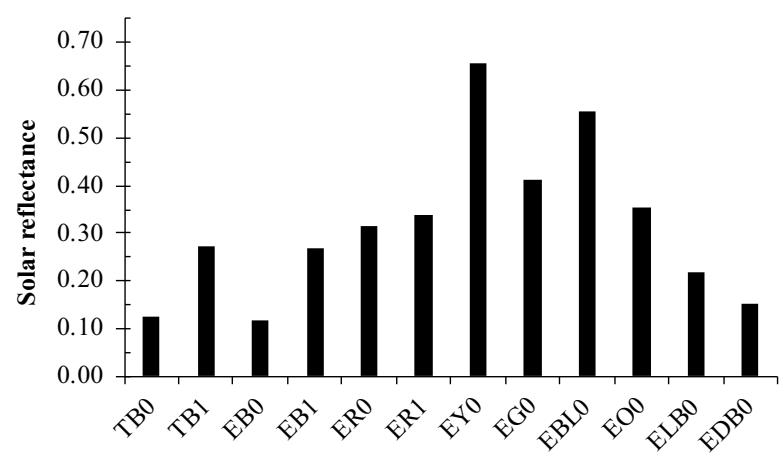

Fig. 4. Values of solar reflectance non-ASTM E1918A.

It is possible to confirm on Fig. 4 that light colours have a higher reflectance value. Moreover, the results show that the incorporation of nanopigments (specimens ended with 1) increases the reflectance, for specimens with the same colour.

Regarding the different insulation slab (specimens started with $\mathrm{T}$ and $\mathrm{E}$ ), it was possible to conclude that this variable has no influence on the solar reflection results, since the values of TB0 are similar to EB0, and TB1 is similar to EB1. These results were expected since the solar reflectance is highly influenced by the finishing coating.

The adopted methodology mitigates all the environmental influences described by Levinson, Akbari and Berdahl [16]. Moreover, for the case of E1918A procedure, the roughness of the specimen is not a factor that affects the results.

Fig. 5 shows the average diffuse solar reflectance for 50 and 100 ordinates, using the spectrophotometer technique.

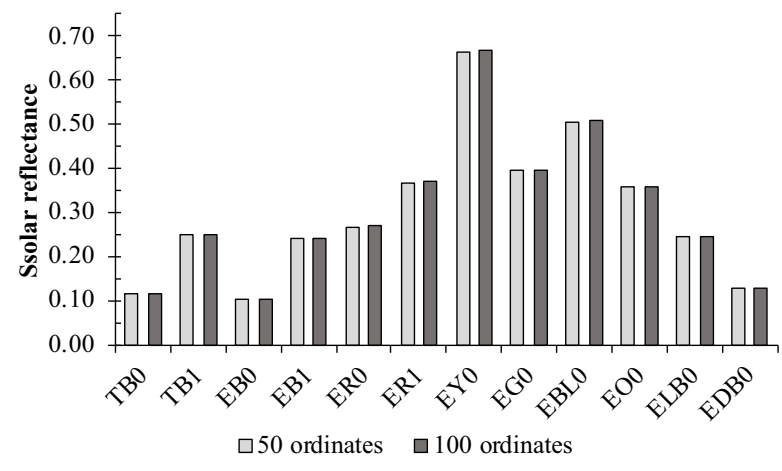

Fig. 5. The difference for ordinates spectrophotometer.

The variation of the diffuse solar reflectance calculated by the two methods ranges from $0.20 \%$ to $0.90 \%$. The maximum absolute difference is 0.005 . These results had errors lower than the uncertainties recommend by the ASTM E903 [16].

The founded results by the spectrophotometer method show the same trend as the results founded by the nonASTM E1918A. The light colours have higher values of solar reflectance than dark colours. Also, it is possible to infer that the nanopigments influence the reflectance, and, the insulation slab was not relevant for the reflectance values. 


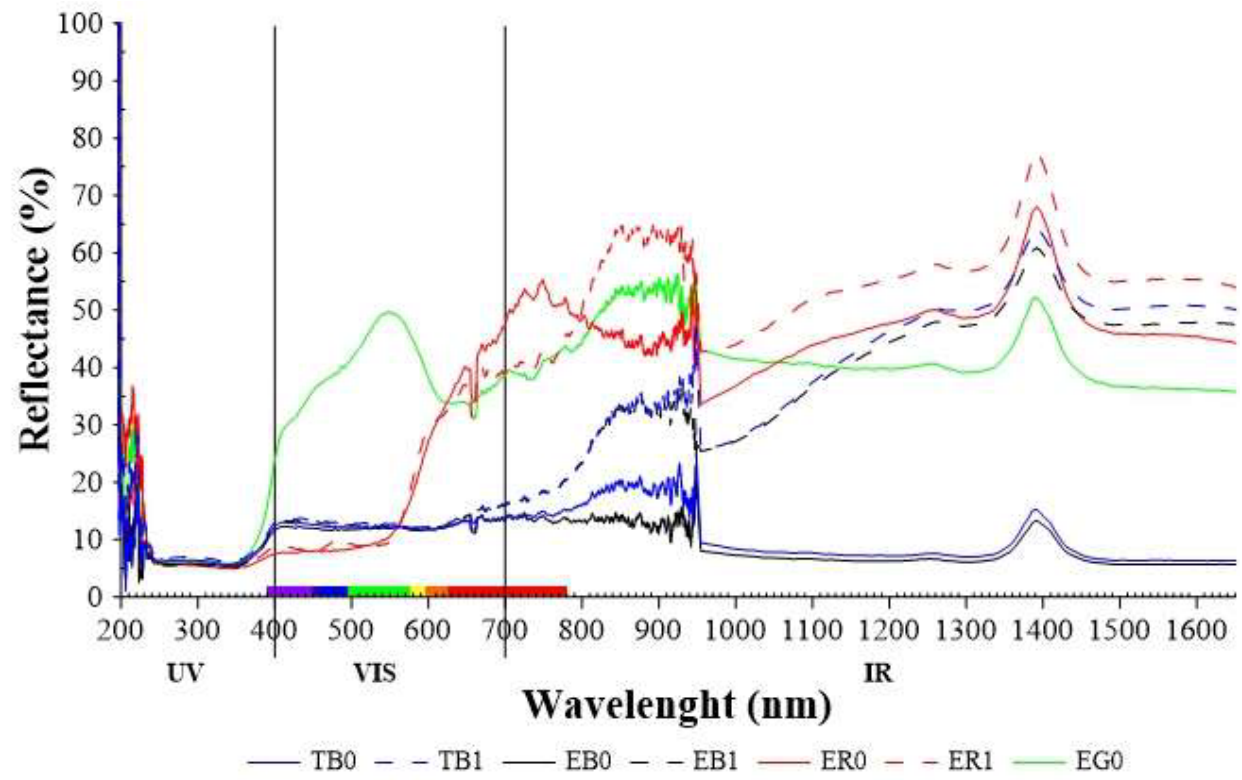

Fig. 6. Spectral distribution of solar reflectance.

\subsection{Influence of roughness}

Studies made by Zinzi, Carnielo and Rossi [10], BarberoBarrera, Campos-Acosta and Niela-González [19] Levinson et al. [20] reported that the roughness of the specimens could be an important contributor to the variation of the solar reflectance.

The finishing coating of the ETICS presents a rough surface. So, in the case, to evaluate the effect of roughness in the variation of the measurements, one of the specimens was evaluated at nine different points.

Fig. 7 present the average of the three measurements of solar reflectance that were carried oud at the nine different points of the EB0 specimen. Furthermore, the pie chart represents the percentual variation of the point measure to the average value of the solar reflectance of the specimen.

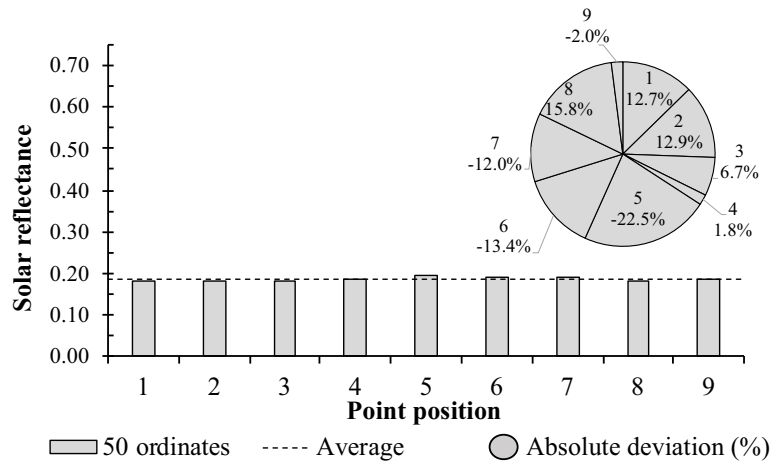

Fig. 7. Variability of diffuse reflectance.

The variation of the nine readings was between $2 \%$ and $22 \%$, with a maximal absolute variation of 0.04

The effect of the points position for the reflectance was higher than the one found by Levinson, Akbari and Berdahl [16].

Analysing the results, it was not possible to establish a correlation between the point location and the reflectance value.

\subsection{Spectral reflectance evaluation}

One of the advantages of using the spectrophotometer is the possibility of analysing the spectral reflectance and the reflectance distribution with the wavelength [21].

Fig. 6 illustrates the spectral distribution of the black (with and without nanopigments), red (with and without nanopigments) and green specimens

Analysing the spectral distribution, Fig. 6, it can be concluded that each colour has a higher reflection at the wavelength corresponding its colour: in the case of the green (EG0) is between $490-570 \mathrm{~nm}$; and for red (ER0 and ER1) is between $630-750 \mathrm{~nm}$.

The spectrophotometer used in this research has two different sources of light, one for the UV-VIS region and another for the IR. The IR band begin at $930 \mathrm{~nm}$, and the UV-VIS ended in $1040 \mathrm{~nm}$. This overlap affects the lecture, inducing noise, resulting in peak values in the band of $930 \mathrm{~nm}$. This effect cannot be corrected since it is an optical property.

Fig. 8 illustrates that the dark colours have a lower solar reflection for the VIS and IR fraction, while the incorporation of nanopigments increases the IR fraction and the average reflection values.

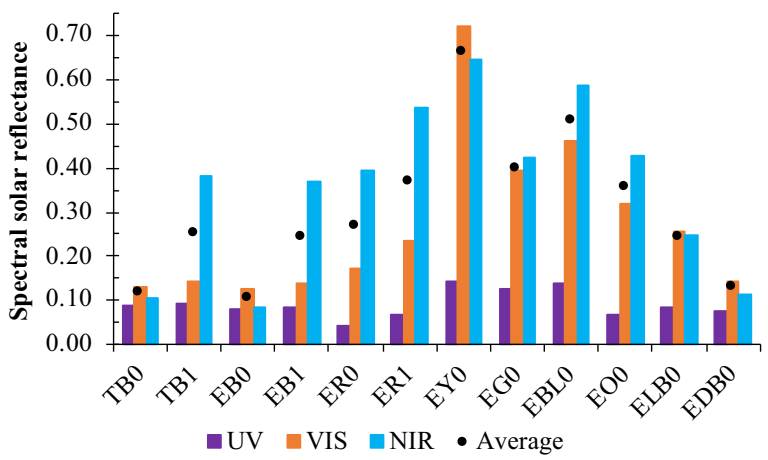

Fig. 8. Spectral values of solar reflectance non-ASTM E903A.

\footnotetext{
${ }^{*}$ Corresponding author: nmmr@fe.up.pt
} 
The influence of the nanopigments on the IR spectral was expected since is the main property of this material. Also, it is possible to conclude that the total solar reflectance is affected by the VIS/IR spectral for the colours without nanopigments. The influence of the VIS/IR and the nanopigments with higher IR reflectance also was verified by Revel et al. [22].

\subsection{Comparison between results}

Table 2 presents the values for solar reflectance by the two methods.

Table 2. Solar reflectance

\begin{tabular}{|c|c|c|c|}
\hline \multirow{2}{*}{ Specimens } & \multirow{2}{*}{ Pyranometer } & \multicolumn{2}{|c|}{ Spectrophotometer } \\
\cline { 3 - 4 } & & $\mathbf{n 5 0}$ & $\mathbf{n 1 0 0}$ \\
\hline TB0 & 0.124 & 0.116 & 0.117 \\
\hline TB1 & 0.273 & 0.250 & 0.252 \\
\hline EB0 & 0.117 & 0.105 & 0.105 \\
\hline EB1 & 0.269 & 0.243 & 0.244 \\
\hline ER0 & 0.314 & 0.269 & 0.270 \\
\hline ER1 & 0.339 & 0.368 & 0.371 \\
\hline EY0 & 0.656 & 0.664 & 0.669 \\
\hline EG0 & 0.412 & 0.397 & 0.399 \\
\hline EBL0 & 0.556 & 0.507 & 0.511 \\
\hline EO0 & 0.355 & 0.358 & 0.361 \\
\hline ELB0 & 0.217 & 0.245 & 0.247 \\
\hline EDB0 & 0.154 & 0.128 & 0.128 \\
\hline
\end{tabular}

The higher variation of absolute value for solar reflectance was of 0.048 for the blue colour (EBL0), and the minimal was of 0.003 for the orange specimen (TO0). The average difference between the results is $2.2 \%$.

The results point to a relation between the specimens colour and the variation of the solar reflectance. The light colours - as yellow, green, blue and orange - have higher reflectance values when measured by the E1918A method, while dark colours, like black and brown, have a minimal difference between the methods.

The influence of the colours also was verified by Barbero-Barrera, Campos-Costa and Neila-González [19].

Fig. 9 present the variability of the results for the orange and blue colours.

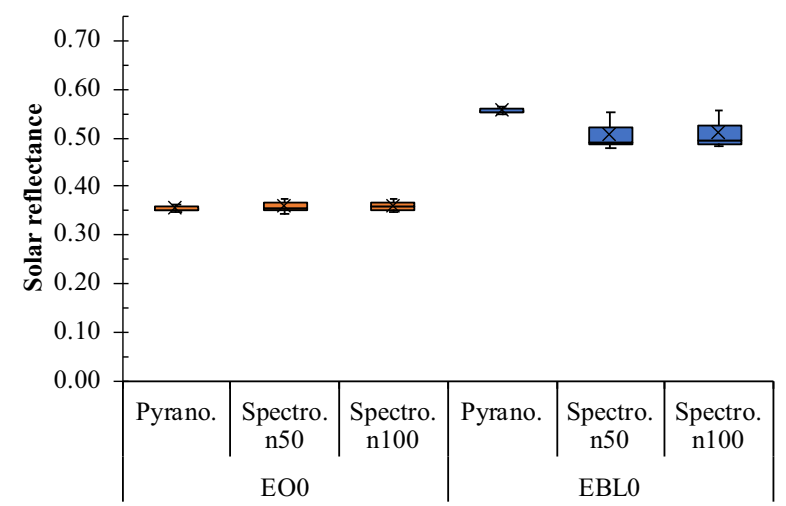

Fig. 9. Variability of the results: orange and blue specimens.

The results with spectrophotometer provides a superior amplitude of results than the pyranometer. The lower variability of the pyranometer method can be explained by the methodological process that just validates values for a fixed amplitude.

The variability of the spectrophotometer can also be explained by the methodology, once it is not fixed a minimal number of repetition. Moreover, the reflection of the light beam in the specimen surface varies with the position.

However, the maximum difference of the results is closer to was found by other studies as Levinson, Akbari and Berdahl [16] and Barbero-Barrera, Campos-Costa and Neila-González [19].

The correlation between the results of the two methods is illustrated in Fig. 10.

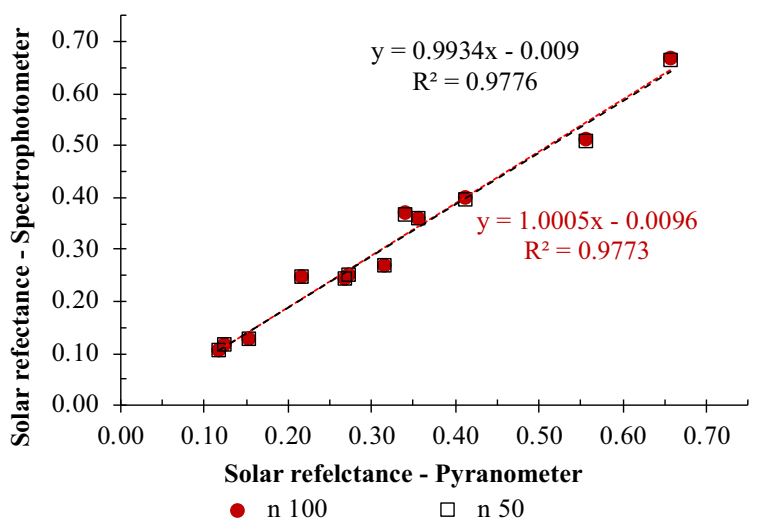

Fig. 10. Correlation of the results of spectrophotometer and pyranometer methods.

The results show a good correlation between the methods. Although the recommendations that the pyranometer should be used in field conditions and the spectrophotometer at a laboratory, both types of equipment proved to be capable of measuring the solar reflectance in the field under exposed conditions.

The good correlation contributes to the results of Zinzi, Carnielo and Rossi [10] that rough surface do not have a relevant specular reflectance, once the total reflectance measure by non-ASTM E1918A is similar to the results of the diffuse reflectance determinate with the spectrophotometer as proposed in this study as nonASTM E903A.

\section{Conclusions}

The following conclusions can be drawn from the experimental campaign carried out in this research:

- The surface colour is very relevant to the solar reflectance of the coatings;

- The nanopigments improve the solar reflectance, and affect the IR spectral;

- The two experimental techniques proved to be capable of measuring the solar reflectance on exposed conditions. The maximum difference between the spectrophotometer and E1918A techniques was 8.4\%;

- For the spectrophotometer used in this research, it was found a perfected correlation between the values calculated with 50 and with 100 ordinates;

- The use of the spectrophotometer is more sensible to the experience of the operator and requires a calibration procedure. 
- The roughness of the surface can bias the measurements carried out with the spectrophotometer. Differences of up to $22 \%$ were found, when measuring different points of the same specimen.

The results showed that both methods can be applied for measuring solar reflectance of ETICS finishing and detected the influence of the nanopigments. However, it is recommended that the choice of an experimental method should be made taking into account not only the available equipment but also the exposure conditions.

This work was financially supported by Project PTDC/ECICON/28766/2017 - POCI-01-0145-FEDER-028766 funded by FEDER funds through COMPETE2020 - Programa Operacional Competitividade e Internacionalização (POCI). The authors also acknowledge to Saint-Gobain Weber to the materials supply.

\section{References}

1. A.L. Pisello, R. Paolini, M.V. Diamanti, E. Fortunati, V.L. Castaldo, L. Torre, in: F. Pacheco Torgal, C. Buratti, S. Kalaiselvam, C.-G. Granqvist, V. Ivanov (Eds.), Nano Biotech Based Mater. Energy Build. Effic., 1-496 (2016).

2. ASTM, E1980 Standard Practice for Calculating Solar Reflectance Index of Horizontal and LowSloped Opaque Surfaces, (2001).

3. EAE, European Guideline for the Application of ETCIS, (2011).

4. H. Akbari, R. Levinson, P. Berdahl, in: Present. Am. Counc. Energy Effic. Econ. Summer Study, 1-9 (1996).

5. H. Akbari, R. Levinson, S. Stern, Sol. Energy, 82, 648-655 (2008).

6. A. Fernández-García, F. Sutter, L. MartínezArcos, C. Sansom, F. Wolfertstetter, C. Delord, Sol. Energy Mater. Sol. Cells, 167, 28-52 (2017).

7. J. Chen, Z. Zhou, J. Wu, S. Hou, M. Liu, Constr. Build. Mater., 202, 46-57 (2019).

8. ASTM, G173 Standard Tables for Reference Solar Spectral Irradiances: Direct Normal and Hemispherical on $37^{\circ}$ Tilted Surface, (2012).

9. E. Coser, V.F. Moritz, A. Krenzinger, C.A. Ferreira, Polímeros, 25, 305-310 (2015).

10. M. Zinzi, E. Carnielo, G. Rossi, Sol. Energy, 115, 52-67 (2015).

11. G. Vox, A. Maneta, E. Schettini, Biosyst. Eng., 144, 26-37 (2016).

12. H. Li, J. Harvey, A. Kendall, Build. Environ., 59, 536-546 (2013).

13. C. Meola, S. Boccardi, G. maria Carlomagno, in: Infrared Thermogr. Eval. Aerosp. Compos. Mater., 57-83 (2017).

14. R. Levinson, H. Akbari, P. Berdahl, Sol. Energy, 84, 1717-1744 (2010).

15. ISO, ISO 9060 Solar Energy - Specification and Classification of Instruments for Measuring Hemispherical Solar and Direct Solar Radiation, (2018).

16. R. Levinson, H. Akbari, P. Berdahl, Sol. Energy, 84, 1745-1759 (2010).

17. ASTM, E903 Standard Test Method for Solar
Absorptance, Reflectance, and Transmittance of Materials Using Integrating Spheres, (2012).

18. ASTM, E1918 Standard Test Method for Measuring Solar Reflectance of Horizontal and Low-Sloped Surfaces in the Field, (2016).

19. M.M. Barbero-Barrera, J. Campos-Acosta, F.J. Neila-González, Energy Build., 76, 615-621 (2014).

20. R. Levinson, S. Chen, P. Berdahl, P. Rosado, L.A. Medina, Sol. Energy, 100, 159-171 (2014).

21. S. Krimpalis, D. Karamanis, Energy Build., 97, 137-145 (2015).

22. G.M. Revel, M. Martarelli, M. Emiliani, A. Gozalbo, M.J. Orts, M.Á. Bengochea, L. Guaita Delgado, A. Gaki, A. Katsiapi, M. Taxiarchou, I. Arabatzis, I. Fasaki, S. Hermanns, Sol. Energy, 105, 770-779 (2014). 